\title{
GLOBALIZACIÓN Y REGIONALIZACIÓN: BUSCANDO EL FONDO Y SU RAZÓN
}

\author{
Por \\ Raúl Fernández* \\ Alberto Abello** \\ RESUMEN
}

\begin{abstract}
El actual discurso de la globalización, con sus implicaciones económicas, políticas y tecnológicas, se ha presentado como la forma de organización mundial que integrará a los países del mundo, aun a los del tercero, a un sistema de economía de mercado. Ante esta promesa de crecimiento y prosperidad para todos, en este ensayo se realiza una reflexión crítica sobre las "bondades" de este nuevo orden mundial, de su modelo económico neoliberal y las teorías del desarrollo regional en detrimento de las autonomías nacionales.
\end{abstract}

\begin{abstract}
This discourse on globalization, with its economic, political and technological implications, is presented to show a kind of world organization which will integrate the countries of the world, including third-world countries, forming an economic market system. While considering this promise of growth and properity for all, the essay takes a critical look at the "blessings" of such a new world order, its neoliberal economic model, and the theories of regional development detrimental to national autonomy.
\end{abstract}

\section{UN MUNDO DE SUPERFICIES}

La retórica internacional del momento da la bienvenida a la globalización que se nos aparece como un inmenso raudal de innovaciones y cambios económicos y tecnológicos, cuya principal manifestación, es el incremento de los flujos de capital en una "aldea global" a la que se incorporan países aislados y estatizados que supuestamente se encontraban al margen de la corriente de las economías de mercado. Con ella, el concepto de nación como ente autónomo pierde importancia y el de región adquiere más relevancia.

Los cambios en el transporte y las comunicaciones, producto de la revolución científica y tecnológica de la década de los ochenta, introduce

* Universidad de California en Irvine.

** Departamento Nacional de Planeación, Bogotá, Colombia. 
nuevos sistemas que, al aplicarse a la producción y al comercio internacional, dan la apariencia de una situación que los teóricos han llamado como "la nueva economía de geometría variable" por generar posibilidades para la descentralización territorial de los procesos productivos.

El aparecido discurso tecnologista se repite por todas partes, y llama a la humanidad a subirse al tren que la llevará a la estación final de la historia, a la concurrencia de un mercado global y a una competencia de producción de bienes y servicios a la que habrían de acudir naciones del norte y del sur, pequeñas y grandes, del centro y la periferia.

Es una nueva tierra prometida, donde habría prosperidad y crecimiento económico para todos.

\section{LA CONTIENDA DE LAS POTENCIAS}

La prosperidad de Estados Unidos, el país más avanzado, se ha deteriorado durante los últimos veinte años y la tasa de ganancia de sus empresas decrece: simultáneamente desde los años sesenta una proporción cada vez mayor de sus ganancias corporativas ocurren en el exterior.

Por otro lado, liberado occidente del enemigo militar soviético, americanos, nipones y germanos que competían a fuego lento, prenden la llama de la hoguera de una batalla comercial sin precedentes y se precipitan al mundo en busca de mercados y de mano de obra barata, calificada y disciplinada. Es notorio el esfuerzo de las multinacionales por extender sus inversiones y ampliar su comercio al desplomarse el imperio soviético. Occidente se desbarata como bloque.

Los países sedes de los grandes monopolios y ellos mismos impulsan directamente y a través de organismos multilaterales una serie de políticas para intentar resolver sus problemas: políticas que en diferentes contextos adquieren distintos nombres: descentralización industrial en Europa, integración y libre comercio en México; apertura en el caso de Colombia y algunos países latinoamericanos, y regionalización para todo el mundo. El Banco Mundial y el Fondo Monetario Internacional establecen la condicionalidad de la asistencia externa a la aplicación de estas políticas.

En el plano de la política económica, la globalización coincide con la irrigación del llamado modelo neoliberal impulsado, en un principio, por los gobiernos de Margaret Tatcher y Ronald Reagan en Inglaterra y Estados Unidos a todo el planeta.

Un antecedente importante de la globalización ocurre cuando el gobierno de los Estados Unidos propone negociaciones comerciales por separado con países o grupos de países de América Latina, ofreciendo potenciales beneficios sobre la base de una apertura económica a productos 
1. inversiones norteamericanas. Es la llamada Iniciativa Bush para las Américas que busca extender la maquila a nivel continental, promover el modelo neoliberal y resolver el problema de su déficit comercial con el Japon, vendiendo sus mercancías por todo el continente libre de trabas, larilas, impuestos y cualquier medida diseñada para la protección del uparato productivo de las naciones latinoamericanas. Estados Unidos impulsa el avance de estas políticas a niveles gubernamentales, restablece su hegemonía militar sobre el Caribe, invade a Panamá, establece bases militares por los países andinos, so pretexto de combatir el narcotráfico, apoya abiertamente políticos y partidos de acuerdo con sus planteamientos y enaltece en el marco internacional a toda una gama de tecnócratas del nuevo orden internacional.

Mientras los países industrializados del hemisferio norte se lanzan a una batalla comercial, los de abajo, después de la llamada década perdida se ven abocados a la nueva panacea de la globalización cuando países como los de toda América Latina se han sumado a la reorientación de sus economías aplicando la desestatización y liberación de los mercados de capital, de bienes y servicios y laboral, que bien puede traducirse en la caída de los salarios reales, la retracción del consumo, el deterioro de los servicios públicos, la salud, la educación, la vivienda y el agravamiento general de las condiciones de vida de la población.

Tan agudo ha sido el proceso de los últimos cinco años, tan aguda es la ecuación neoliberalismo-empobrecimiento, que una ola de gobernantes electos y por elegir se han visto obligados con el beneplácito de la banca multilateral a suavizar el recetario neoliberal y diseñar paquetes "compensatorios", de "solidaridad social", con "rostro humano", para "ponerle corazón" al modelo."

La llamada aldea global presenta por lo tanto un escenario que no es homogéneo; los países no están en condiciones de asistir a ella en pie de igualdad.

\section{LOS ENSAYOS DEL NEOLIBERALISMO}

La globalización aparece como la resultante de la confluencia de factores estructurales y coyunturales de las economías de mercado de las

\footnotetext{
1 Ver Centanino Horacio. "Las preocupaciones sociales del nuevo presidente de Colombia". Diario La Opinión de Los Ángeles. Jueves 22 de septiembre de 1994. En un artículo periodístico se señala cómo Carlos Reina de Honduras, Caldera de Venezuela, Figueres en Costa Rica y Samper en Colombia, ganaron sus contiendas respectivas apartándose del recetario neoliberal puro y duro. Lula en Brasil y Tabare Vásquez en Uruguay comparten asimismo esa fórmula.
} 
naciones desarrolladas. No es un concepto teórico. El término es acuñado por las grandes corporaciones internacionales, los paises industrializados y las agencias de desarrollo para explicar la nueva ofensiva sobre el orbe.

Se trata de que los países industrializados y las transnacionales buscan mano de obra barata, recursos básicos y mercados que les permitan alejarse de la crisis haciendo sus operaciones redituables y garantizando la venta de sus productos. La globalización es una estrategia para contrarrestar la enorme superproducción de bienes y servicios en los países avanzados y la caída de la tasa de ganancia de las grandes corporaciones (ver figura 1).

Anteriores experiencias del capital internacional focalizadas en ciertos territorios del planeta y la revolución del transporte y las comunicaciones, se suman para ser aplicadas a todo el mundo y facilitar el objetivo final.

Se validan y reproducen las experiencias particulares como la maquila de México, las "zonas de exportación" de la costa china y la utilización de regiones deprimidas en Europa como es el caso de Italia en los ochenta.

En el caso de México de los años sesenta numerosas compañías estadunidenses trasladaron gran parte de sus operaciones a la franja fronteriza de este país donde aprovechan el trabajo barato de, en su mayoría, jovenes mujeres mexicanas en tareas de ensamblaje. La maquila del norte de México emplea docenas de miles de obreras, muchas de ellas adolescentes que obtienen salarios ínfimos y laboran en condiciones deplorables que se caracterizan en particular por la toxicidad del medio ambiente. La industria de la maquila en México le permite a las grandes compañías estadunidenses competir con Japón en el mercado internacional pero no ha resuelto el formidable problema del desempleo y el bienestar ni en la frontera ni en el resto del país latinoamericano. Más bien ha trafdo como consecuencia una enorme inmigración de otras ciudades y del campo de México por parte de campesinos arruinados y obreros desempleados ansiosos de encontrar trabajos remunerativos.

La experiencia de China demuestra que, lejos de ser sólo un problema fronterizo como el caso mexicano, la utilización de mano de obra barata femenina tiene características más generales e igualmente desastrosas. En los años ochenta más de dos millones de jóvenes chinas fueron reclutadas para las zonas de exportación donde trabajan en condiciones infrahumanas (v.g. las trabajadoras de estas zonas preparan sus alimentos de pie en recovecos de las factorías, utilizan cuartos comunales como duchas, y duermen apiñados en los mismos sitios donde laboran jornadas de diez, doce y catorce horas). En los últimos años las precarias condiciones de las fábricas han causado mortales incendios, en el último de los cuales más de doscientas adolescentes murieron calcinadas ya que la fábrica donde laboraban no poseía puertas de escape de emergencia en caso de incendio. 


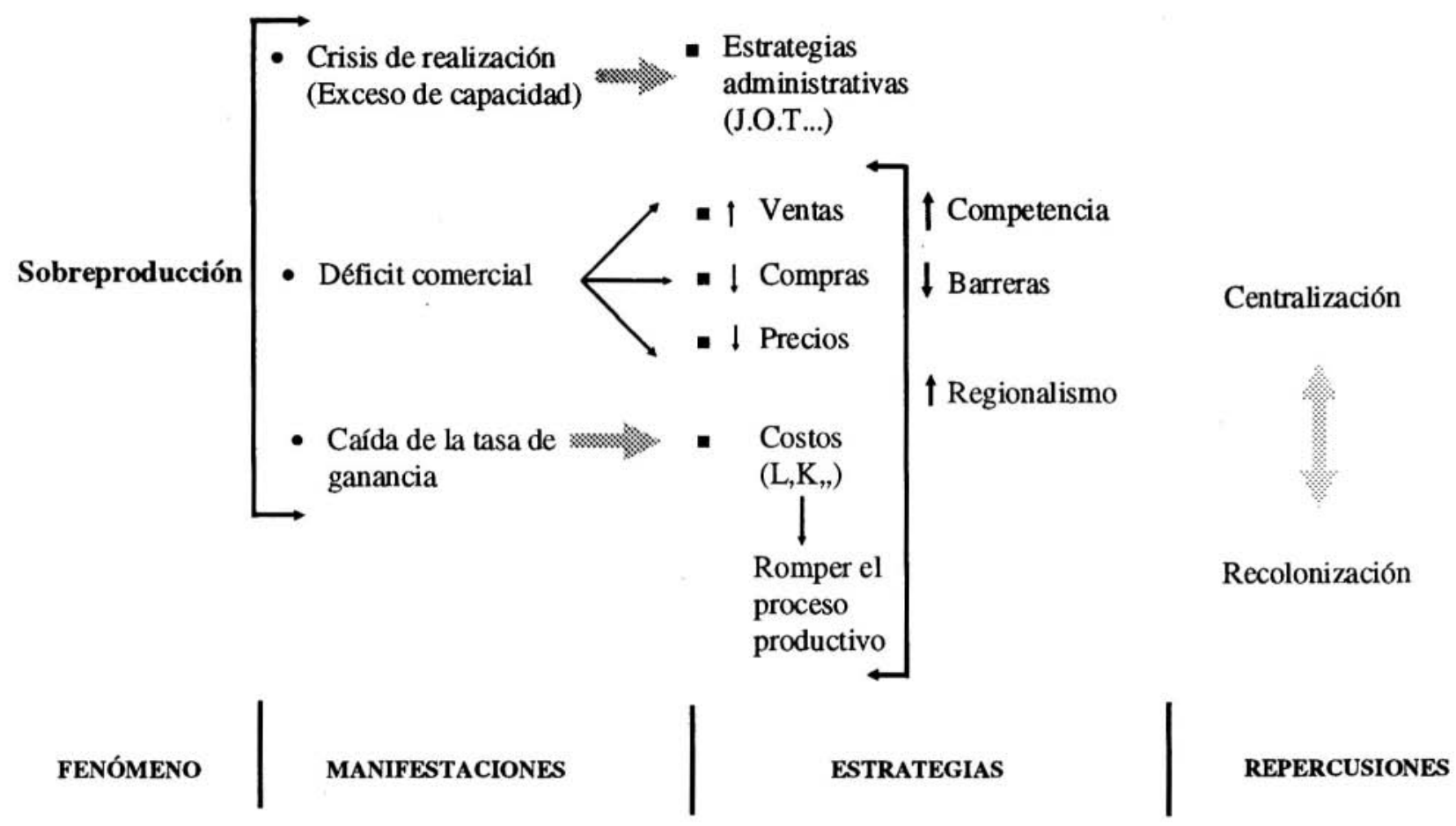

Figura 1. Causa y efecto de la globalización. 
En Europa, en la década de los ochenta, y en respuesta a la crisis que cundió por todo el continente, se puso de moda el crecimiento industrial basado en el modelo de desarrollo italiano. Este último consistra en la utilización de las zonas más atrasadas del país con el más desigual desarrollo de la Comunidad Económica Europea - en aquel momentopara utilizar una vez más mano de obra barata; con un detalle adicional, la utilización de la pequeña empresa como válvula de escape (en Sicilia y Calabria), como basamento para la recuperación industrial de los grandes centros europeos.

Estas experiencias de utilización de mano de obra barata en zonas deprimidas del mundo se vieron como generalizables con la máxima utilización de las llamadas tecnologías modernas de CAD (Computer Assisted Design), caM (Computer Assisted Manufacturing) y su lógica consecuencia para uso del capitalismo, el FIM (Flexible Integrated Manufacturing). Tecnologías que permiten fraccionar y diseminar en distintos puntos del globo los procesos productivos ligados a cadenas de montaje que buscan maximizar la productividad y la rentabilidad de la localización espacial, utilizando la subcontratación; el ensamble, la industria a domicilio, y a pequeños empresarios; fenómenos todos ellos que en la nueva literatura se conocen con el nombre de la "producción flexible" o el "postfordismo" y para los que es preciso romper la "fricción del espacio" y unir los territorios dispersos con la creación de "regiones virtuales" (Scott, 1988).

Pero es claro que las ventajas de la nueva situación no obedecen solamente al fenómeno tecnológico, la utilización de la tecnología de esta manera ha requerido de la "flexibilización" del mercado laboral en Latinoamérica, África y Asia lograda por medio de reformas a la legislación.

Con el nuevo esquema y el traslado de procesos a territorios alejados de la casa matriz, éstas se desembarazan de las condiciones laborales y de vida de sus trabajadores. Coincide entonces con las reformas laborales que traen consigo la baja de los salarios, el aumento de la duración de los contratos a término fijo, la formalización de agencías de empleo temporal, el aumento del periodo de prueba y la disminución de la protección contra despidos colectivos. Es decir, se flexibiliza toda norma laboral que desde el punto de vista del capital encarezca la mano de obra o establezca "rigideces a su movilidad".

En ese camino por hacer sus operaciones redituables y contrarrestar la caída de la tasa de ganancia, los grandes consorcios de los principales países industrializados engullen por todo el mundo a pequeñas empresas y se apoderan de los sectores privatizados por la ola neoliberal, generando un asombroso proceso de centralización y concentración de capitales. 


\section{LA COMPETITIVIDAD DE LAS NACIONES POBRES}

Los países pobres comienzan a competir intensamente entre sí tratando de eliminar cualquier barrera que impida la absoluta movilidad del capital y la utilización de la mano de obra barata. Compiten con legislación laboral, de comercio externo, sobre el tratamiento al capital extranjero, el manejo de los recursos naturales y la diversidad biológica, el manejo de las condiciones ambientales y el ordenamiento territorial. Medidas que conllevan sustanciales rebajas a la autonomía nacional.

De esta forma, millones de hombres y mujeres han sido lanzados a trabajar en maquilas y en industrias a domicilio desde los barrios de Puerto Principe en Haití y Ciudad Guatemala, pasando por Lagos de Nigeria, y la Calcuta de la India, donde las modernas mercancías del mundo del consumidor son producidos para la exportación (electrodomésticos, ropa, calzado, juguetes, muebles y todo producto que requiera mano de obra para procesos de ensamblaje).

Este nuevo modelo neoliberal de la globalización, el carnaval de la producción flexible a nivel mundial, incrementa las disparidades entre y dentro de los países a través del mundo. Con un potencial resultado sugerido en una frase de Manuel Castells de que la corporación moderna busca la aplicación de una tecnología del siglo XXI con una fuerza laboral al estilo del siglo XIX.

\section{LO VIEJO Y LO NUEVO}

La aplicación de los adelantos científicos a la producción por medio de las innovaciones tecnológicas facilitan cambios en la estructura organizacional de las firmas, en el manejo de los negocios, en las decisiones determinantes para la localización espacial y en la estructura y las funciones gubernamentales. Las nuevas tecnologías, principalmente en los sectores de transporte, comunicación e informática, que permiten la utilización de ayudas del computador para el diseño y fraccionamiento de los procesos productivos, traslado multimodal de la carga, y el manejo de datos sobre el comportamiento de los precios de los factores en el planeta entero, facilitan a las corporaciones que están en capacidad de absorberlas, la introducción de modificaciones en su estructura organizacional y en el manejo de los negocios: crecen las actividades de servicios y en una perspectiva internacional se incrementan los sistemas de produccion utilizando pequeñas firmas y microempresas que usan materia prima y mano de obra barata. La industria se descentraliza y crecen los empleos precarios, temporales y de medio tiempo. 
De esta forma, las viejas industrias se desplazan a la periferia, y las decisiones de localización espacial, que antes se determinaban por la cercanía a las fuentes de recursos, a los proveedores o al mercado, se toman en aquellos territorios que les representan menores costos y mayores beneficios para su estrategia global.

Las migraciones de capital ocurren hacia zonas deprimidas tanto de los países industrializados como del tercer mundo. En los Estados Unidos una regionalización de las inversiones proveniente de los centros industriales se ha orientado hacia Carolina del Norte, Georgia y Alabama durante los últimos años.

Esta expansión del capital a escala mundial requiere la eliminación de fronteras y la reducción de barreras que obstaculizen los nuevos flujos. Una menor autonomía nacional, especialmente en los países más pobres, es concomitante con la nueva modalidad. Reformas gubernamentales en éllos promueven la descentralización administrativa hacia niveles locales y regionales, restan capacidad de negociación frente al extranjero a los gobiernos centrales y otorgan a regiones y provincias mayor autonomía para hacer negocios, a la vez que se toman por asalto los sistemas de beneficio social.

Pero no es la primera vez que ocurre un proceso como este, en el que el desarrollo de las fuerzas productivas permite la utilización de relaciones de producción atrasadas, para dar paso a un proceso de acumulación a escala mundial en el que entran en juego los recursos de los territorios apartados del centro de las actividades económicas.

En dos ocasiones en el último milenio han ocurrido procesos similares de globalización simultáneamente con el desarrollo del comercio y la tecnología. En el siglo XVI, la conquista de los incas, aztecas y otros pueblos indígenas del hemisferio coincide con la primera gran ola globalizadora. El desarrollo del mercado fue acompañado por el pillaje de América, la exterminación de los indígenas, el robo de los metales preciosos, la forzada esclavitud de millones de africanos. El desarrollo del comercio dio paso a nuevos cambios tecnologicos del transporte y las comunicaciones, que a su vez contribuyeron a la formación del mercado mundial y a la consolidación del capitalismo, que se alcanza sobre la base de métodos de producción atrasados como lo fueron la esclavitud y el feudalismo implantados en América Latina.

En el siglo XVIII y comienzos del XIX la revolución industrial otra vez dinamiza una expansión del comercio y la tecnología. Por primera vez, ciertos países comienzan a llamarse industrializados. Masas de campesinos, con frecuencia a la fuerza, abandonan sus rústicos hogares para conformar un nuevo proletariado urbano en las grandes ciudades europeas. 
El enorme sufrimiento humano que acompañó esta transformación ha sido descrito en páginas inmemorables en la narrativa de Charles Dickens. Avances tecnológicos que comenzaron en la industria textil y que más tarde llegaron al transporte y las comunicaciones (tren, vapores, telégrafos, canales), originan una segunda globalización con la que las grandes potencias (Inglaterra, Francia, Alemania y Estados Unidos) se reparten el continente negro de África, colonizan la India, desmembran a China, se hacen dueños de la península de Indochina e intentan subyugar al Japón. Durante las últimas dos décadas del siglo XIX se vive un intenso proceso de concentración y acumulación de capitales; aparecen los cartels, trusts y las grandes corporaciones.

Como las ocasiones previas, el actual periodo de globalización también coincide como se ha señalado antes, con el crecimiento del comercio, la inversión y el desarrollo de la tecnología. Pero también es acompañada, como se ha anotado, del incremento de desigualdades y pobreza entre países y el retorno a formas atrasadas de producción (ver figura 2).

\section{LA CRISIS DE LAS TEORÍAS DEL DESARROLLO}

En el actual periodo, regiones y ciudades de todo el orbe juegan un papel clave. Los teóricos de la globalización hacen uso de frases como "la competitividad internacional" y el "desarrollo del potencial endogeno" de las regiones para anunciar el acomodamiento de las teorías del desarrollo regional a la cambiante situación del panorama internacional.

El mismo concepto de región empieza a cambiar. Mientras las viejas teorías la definían como una unidad física, económica, social y cultural, las nuevas versiones sugieren, para ponerse a tono con la nueva era postmodernista, la "región virtual", que permite incorporar un territorio cualquiera que este sea (barrio, ciudad o zonas especiales) a uno o varios de los procesos de la producción flexible internacional. ${ }^{2}$

Los teóricos de la nueva ortodoxia repiten el concepto de regionalización en tandem con el concepto de globalización (Boisier, 1992), pero se abstienen en absoluto de referirse a la nación o al desarrollo nacional.

Países del tercer mundo diseñan estrategias para reordenar la organización de sus territorios y comienzan a declarar algunas de sus provincias como autónomas, lo que les permite la búsqueda por su propia cuenta, e independientemente de las ya disminuidas reglas laborales y ambientales a nivel nacional, de acuerdos por separado con multinacionales que puedan

2 Sergio Boisier en su intervención en el primer seminario internacional sobre región organizado por Proregión. Cartagena. Colombia. 1994. 
de esa forma coordinar su producción flexible o extraer petróleo, minerales o biogenética en negociaciones con gobiernos locales. Claro que los compromisos adquiridos por las regiones habrán de ser refrendados por los estados nacionales, los que a pesar del debilitamiento propuesto no dejan de ser imprescindibles.

Hoy las agencias internacionales pregonan la obsolecencia de la soberanía nacional, lo que es repetido por la administración Clinton, mientras en el tercer mundo se debilita la capacidad de negociación del estado central a favor de las regiones. Las nociones de desarrollo nacional, y aun de nación, no se contemplan ya por los economistas tradicionales, revelando la bancarrota teórica de sus enunciados.

Globalización y regionalización aparecen como las dos caras de una misma moneda. El concepto de desarrollo nacional es sustituido por el de desarrollo regional, pero las estrategias utilizadas no permiten vislumbrar ninguno de los dos como resultado a esperarse.

La regionalización encaja de manera particular en América Latina, con la descentralización administrativa y fiscal adelantada por recomendación de la banca multilateral a raíz de la crisis de la deuda externa. Descentralización orientada del gobierno central hacia los entes territoriales inferiores a los que se les entregan nuevas funciones relativas a la satisfacción de las necesidades de la población y a la financiación del desarrollo.

Las políticas de descentralización y de privatización, de recorte a los servicios públicos, de desaparición de empresas estatales, están llevando en todos los países del mundo a un incremento del desempleo aunque sea disfrazado con los motes de empleo precario o de economía informal. En Colombia, más del $50 \%$ del empleo en las siete grandes ciudades corresponde a este sector informal que es precisamente la alternativa al desempleo del sector formal de la economía y a los despidos del sector oficial. En México, durante la década de los ochenta, crece la informalidad de la economía y con ella los empleos precarios (Graizbord, 1994).

No es sorprendente que en documentos oficiales que emanan de Washington, la microempresa y la economía informal se publicitan como necesarios ingredientes del nuevo modelo neoliberal de crecimiento.

Hace veinte años, en el primer capítulo de todo texto dedicado al estudio del subdesarrollo, se identificaban concienzudamente las características fundamentales de esta dolencia. El subdesarrollo tenía como característica primordial la presencia del subempleo, y del desempleo disfrazado. La meta de los estudiosos de la economía era la de superar estas falencias, cosa que vendría con el desarrollo económico, pero con el auge de las teorías neoliberales, ellas mismas ahora denominadas microempresa y economía informal, hacen parte de las estrategias para el desarrollo. 


\begin{tabular}{|c|c|c|c|}
\hline & SIGLO XV & SIGLOS XVIII-XIX & FINALES SIGLO XX \\
\hline $\begin{array}{c}\text { DESARROLLO } \\
\text { DEL CONOCIMIENTO }\end{array}$ & $\begin{array}{l}\text { - Contacto con oriente } \\
\text { - Renacimiento }\end{array}$ & $\begin{array}{l}\text { - Revolución } \\
\text { científica }\end{array}$ & - Informática \\
\hline $\begin{array}{l}\text { DESARROLLO } \\
\text { TECNOLÓGICO }\end{array}$ & $\begin{array}{l}\text { - Navegación } \\
\text { - Imprenta }\end{array}$ & $\begin{array}{l}\text { - Industria } \\
\text { - Transporte } \\
\text { - Comunicaciones }\end{array}$ & $\begin{array}{l}\text { - Transporte } \\
\text { - Telecomunicaciones }\end{array}$ \\
\hline $\begin{array}{l}\text { ESTRATEGIA } \\
\text { GLOBAL }\end{array}$ & $\begin{array}{l}\text { - Colonización } \\
\text { mercantilista }\end{array}$ & $\begin{array}{l}\text { - Colonización de libre } \\
\text { comercio }\end{array}$ & - Recolonización \\
\hline
\end{tabular}

\section{Figura 2. Lo nuevo y lo viejo de la globalización.}

Fuente: Elaborado por el autor. 
Los teóricos contemporáneos ven esta situación, no como una transición, sino como la etapa final, la única a que pueden aspirar los países pobres. El menú que se les ofrece es de regionalización, acompañada de informalización.

\section{CONCLUSIONES}

Detrás del slogan de la globalización, lo que contemplamos es una nueva y masiva colonización del planeta por las grandes potencias que publicitan y condenan la soberanía nacional, como concepto obsoleto en su raciocinio de una recolonización de las naciones débiles.

Lo que se da no es un nuevo orden internacional, sino una nueva repartición del globo, en la que las naciones poderosas dirimen sus disputas a través de la formación de bloques como el NAFTA, y utilizan instrumentos como el GATT en el que a tiempo que predican el libre comercio con las reglas de juego por ellos impuestos, impiden y limitan el acceso de los productos de los países pobres a los mercados mundiales y protegen las economías de sus propios países.

Como bien ha dicho Luis Fernando Jaramillo, ex presidente del Grupo de los 77, las naciones subdesarrolladas confrontan después de la Ronda de Uruguay un ambiente internacional hostil y una pérdida sustancial de poder económico y político en el llamado nuevo orden. $Y$ añade Jaramillo, "el bienestar de la mayoría de nuestros pueblos, o no existe, o en el mejor de los casos se ha detenido". 3

La globalización como estrategia de las potencias y los conglomerados económicos no garantiza el desarrollo nacional y mucho menos el desarrollo de las regiones y ciudades receptoras de las inversiones. Se adelanta sobre la base del atraso y la mano de obra barata de los países pobres y las regiones deprimidas del mundo; conduce a una mayor centralización del capital y mantiene la pobreza.

3 Luis Fernando Jaramillo. Discurso de despedida del Grupo de los 77. Nueva York, enero de 1994: De acuerdo con Jaramillo, los países industrializados que representan solamente $20 \%$ de los miembros del GATT se apropiaron del $70 \%$ de los ingresos esperados a partir del nuevo acuerdo del GATT. Esto se debe a que los países desarrollados se beneficiarán mucho más de las rebajas de tarifas en los subdesarrollados que a la inversa. Sobre la Organización de Comercio Internacional, "los términos de su creación nos sugieren que esta organización será dominada por los países industrializados y que su destino será el alinearse con el Banco Mundial y el FMI. Se podría anunciar desde ahora el nacimiento de una nueva trinidad institucional que tendría como función específica el control y dominio de las relaciones económicas que afectan al mundo en desarrollo." 


\section{BIBLIOGRAFÍA}

BOISIER, Sergio, et al. 1992. "La descentralización: el eslabón perdido de la cadena de transformación productiva con equidad y sustentabilidad", Cuadernos del ILPES, núm.36.

CENTENO, Horacio. 1994. "Las preocupaciones sociales del nuevo presidente de Colombia". Diario La Opinión de Los Ángeles, jueves 22 de septiembre.

SCOTT, A. 1988. New Industrial Spaces, Londres, Pion. 